\begin{tabular}{|c|l|}
\hline Title & Relationship between XBP1 genotype and personality traits assessed by TCI and NEO-FFI \\
\hline Author(s) & $\begin{array}{l}\text { Kusumi, Ichiro; Masui, Takuy a; Kakiuchi, Chihiro; Suzuki, Katsuji; A kimoto, T atsuyuki; Hashimoto, Ry ota; Kunugi, } \\
\text { Hiroshi; Kato, Tadafumi; Koyama, T sukasa }\end{array}$ \\
\hline Citation & $\begin{array}{l}\text { Neuroscience Letters, 391(1-2), 7-10 } \\
\text { https://doi.org/10.1016/.neulet.2005.08.023 }\end{array}$ \\
\hline Issue Date & 2005-12-31 \\
\hline Doc URL & http://hdl.handle.net/2115/8420 \\
\hline Type & article (author version) \\
\hline File Information & nsi05.pdf \\
\hline
\end{tabular}

Instructions for use 


\title{
Relationship between XBP1 genotype and personality traits assessed by TCI and NEO-FFI
}

\author{
Ichiro Kusumi $^{1}$, Takuya Masui ${ }^{1}$, Chihiro Kakiuchi ${ }^{2}$, Katsuji Suzuki ${ }^{1}$, \\ Tatsuyuki Akimoto ${ }^{1}$, Ryota Hashimoto ${ }^{3}$, Hiroshi Kunugi ${ }^{3}$, Tadafumi Kato ${ }^{2}$ \\ and Tsukasa Koyama ${ }^{1}$
}

${ }^{1}$ Department of Psychiatry, Hokkaido University Graduate School of Medicine Sapporo, Japan

${ }^{2}$ Laboratory for Molecular Dynamics of Mental Disorders, Brain Science Institute, RIKEN, Wako, Japan

${ }^{3}$ Department of Mental Disorder Research, National Institute of Neuroscience, NCNP, Kodaira, Japan

Correspondence: Ichiro Kusumi, M.D., Ph.D.

Department of Psychiatry, Hokkaido University Graduate School of Medicine North 15, West 7, Sapporo 060-8638, Japan TEL: +81-11-716-1161 ext.5973 FAX: +81-11-706-5081 e-mail: ikusumi@med.hokudai.ac.jp 


\begin{abstract}
There have been several researches on the role of personality in the pathophysiology of bipolar disorder. Recently, a polymorphism of XBP1, a pivotal gene in the endoplasmic reticulum (ER) stress response, was shown to contribute to the genetic risk factor for bipolar disorder. Therefore, in this study, we examined the relationship between the XBP1 gene polymorphism and the personality traits assessed by two self-rating scales, a shortened version of Temperament and Character Inventory (TCI) and NEO-Five Factor Inventory (NEO-FFI) in healthy subjects. The present results suggested that the XBP1 gene polymorphism was associated with the NEOFFI score of neuroticism in female subjects. However, no significant differences in the other personality scale scores of both assessments were observed among normal subjects with $-116 \mathrm{C} / \mathrm{C}, \mathrm{C} / \mathrm{G}$ and G/G genotypes. Further investigations are necessary to examine the relationship in patients with bipolar disorder, or use full version of various self-rating personality assessments.
\end{abstract}

Key words: XBP1; Polymorphism; Personality; TCI; NEO-FFI

Genetic factors significantly contribute to the determination of human personality traits although environmental influence is also important. Personality traits assessed by self-report questionnaires show moderate heritability [5]. Such inheritance is ultimately attributable to functional variants of genes programming brain 
development and function [4]. Some of these genes have also been implicated in the susceptibility to various psychiatric illnesses including mood disorders [5]. Several authors have paid attention to the premorbid personality traits of patients suffering from bipolar disorder. For example, Akiskal [1] showed that dysthymic, cyclothymic and hyperthymic temperaments represent putative development pathways to bipolarity in childhood and adolescence with clinically ascertained depressions. Bipolar patients might share a specific personality trait that represents the behavioral expression of some genetic neurochemical diathesis to the disease [2].

Recently, a polymorphism of XBP1 gene that plays a pivotal role in endoplasmic reticulum (ER) stress response was shown to contribute to the genetic risk factor for bipolar disorder [8], although negative findings were also reported [3, 7]. Cell injury may develop under conditions where ER calcium homeostasis and, folding or processing of proteins is disturbed (referred to as ER stress), leading to the activation of unfolded protein response such as suppression of protein synthesis and expression of ER stress-related genes including $X B P 1$ [11]. The polymorphism $(-116 \mathrm{C} \rightarrow \mathrm{G})$ in the promoter region of the XBP1 gene was significantly more common in Japanese bipolar patients (odds ratio=4.6). The XBP1-dependent transcription activity of 116G allele was lower than that of $-116 \mathrm{C}$ allele, and induction of XBP1 expression after ER stress was markedly reduced in the cells with the G allele [8].

Therefore, it is possible that the XBP1 gene polymorphism may be involved in the development of personality specific for bipolar disorder. Recently, Kato et al. [9] reported a statistical trend for association between the XBP1 gene polymorphism and 
the Revised NEO Personality Inventory (NEO-PI-R) scores of agreeableness and neuroticism in healthy Japanese female volunteers. In this study we examined the relationship between the $-116 \mathrm{C} / \mathrm{G}$ polymorphism of the XBP1 gene and the personality traits measured by two representative self-report questionnaires, Temperament and Character Inventory (TCI) and NEO Five Factor Inventory (NEOFFI), in the Japanese healthy male and female subjects.

Two hundred and forty eight biologically unrelated healthy volunteers were all Japanese recruited from laboratory, office or hospital staff at Hokkaido University. They all underwent a direct interview to exclude clinical and family history of psychiatric disorders classified according to DSM-IV. There were 141 males and 107 females, and the average age was 31.6 \pm 9.1 (mean \pm S.D.) years. After complete description of the study, informed consent was obtained from all subjects. The research protocol was approved by the ethics committee of Hokkaido University Graduate School of Medicine.

DNA was extracted from $20 \mathrm{ml}$ of whole blood by standard methods. Genotypes for XBP1 gene -116C/G polymorphism were determined using the TaqMan 5'exonuclease allelic discrimination assay, described previously [6]. Briefly, primers and probes for detection of the SNP are: forward primer 5'-CTGTCACTCCGGATGGAAATAAGTC-3', reverse primer 5'ATCCCTGGCCAAAGGTACTTG-3', probes 15'-VIC-CTCCCGCACGTAACMGB-3', and probe 2 5'-FAM-TCCCGCAGGTAAC-MGB-3'. PCR cycling conditions were: at $95^{\circ} \mathrm{C}$ for $10 \mathrm{~min}, 45$ cycles of $92^{\circ} \mathrm{C}$ for $15 \mathrm{sec}$ and $60^{\circ} \mathrm{C}$ for $1 \mathrm{~min}$. 
After collecting the blood samples, all subjects filled out a shortened version of TCI, which consists of 125 questions with four possible answers [10]. Each score on the 4-point scale can range from 1 (strongly disagree) to 4 (strongly agree). A part of the participants (206 subjects, 119 males and 87 females, age: $32.5 \pm 9.4$ years) completed NEO-FFI, the shortened version of the NEO-PI-R, which consists of 60 questions with 5-point scales. The validity and reliability of the Japanese version of TCI and NEO-FFI have already been confirmed among different Japanese populations $[8,12]$.

Age and sex are known to affect self-rating personality assessments. In order to examine the relationships between the XBP1 gene polymorphism and, TCI or NEOFFI scores, one-way analysis of covariance (ANCOVA) was performed with XBP1 genotype as independent variables, and with age and sex as covariates. Statistical test was carried out using SPSS for Windows. P values less than .05 were considered statistically significant after Bonferroni’s correction for multiple testing.

The TCI and NEO-FFI scores sorted by the $-116 \mathrm{C} / \mathrm{G}$ polymorphism of XBP1 gene are shown in Table I and Table II, respectively. Observed genotype distribution was consistent with Hardy-Weinberg equilibrium. The distribution of the XBP1 genotype in our sample was almost same as in the other Japanese samples [8, 9]. Although there was no significant relationship between the XBP1 -116C/G genotypes and seven personality dimension scores of TCI (Table I), the NEO-FFI score of neuroticism showed a significant association with the XBP1 gene polymorphism in females ( $\mathrm{F}=6.41, \mathrm{p}=0.003)$, not in male or all subjects (Table II). 
No significant associations were observed in the other four dimension scores of NEO-FFI.

If some personality trait might be involved in the vulnerability of bipolar disorder, it should be a continuous factor from normal control to bipolar disorder. On the other hand, the G allele of XBP1 gene, a risk for bipolar disorder, is also observed in normal controls, not only in bipolar disorder [8]. Accordingly, it is of significance to examine the relationship between the XBP1 genotype and the personality traits in normal subjects. The present study partially confirmed the finding of Kato et al. [9] reporting a trend for association between the XBP1 gene polymorphism and the NEO-PI-R scores of agreeableness and neuroticism in healthy volunteers. In contrast to the previous report [9], the present study examined the relationship between the XBP1 genotype and the personality traits assessed by not only NEO but also TCI in both male and female healthy subjects. Thus, it clearly demonstrated that a significant association between the XBP1 polymorphism and the NEO score of neuroticism was observed only in female subjects. This finding suggests that gender differences exist in contribution of genetic factors to behavioral phenotypes. The discrepancy for the finding of agreeableness is unknown, but it may arises from the methodological difference between the two reports that the questionnaire used is full or shortened version of NEO. Further studies are necessary to examine the relationship between the XBP1 genotype and the personality traits in patients with bipolar disorder. The limitation of this study is to use the shortened 
version of TCI and NEO-PI-R. Analyzing subscales in each dimension might enable us to assess more specific facets related to the XBP1 gene polymorphism.

In conclusion, the present study suggests that the XBP1 gene polymorphism is associated with the NEO-FFI score of neuroticism in healthy female subjects. Further investigations are needed to examine the relationship in patients with bipolar disorder, or use full version of various self-rating personality assessments.

\section{Acknowledgments}

This work was partly supported by grants-in-aid for Soul and diseases-of-thenervous-system research (T. Koyama) from Japanese Ministry of Health, Labor and Welfare, and for Scientific Research No. 15591206 (I. Kusumi) from Japanese Ministry of Education, Culture, Sports, Science and Technology.

\section{References}

[1] H.S. Akiskal, Developmental pathways to bipolarity: are juvenile-onset depressions pre-bipolar? J Am Acad Child Adolesc Psychiatry 34 (1995) 754763.

[2] R.H. Belmaker, J. Biederman, Genetic markers, temperament and psychopathology (editorial). Biol Psychiatry 36 (1994) 71-72.

[3] S. Cichon, S. Buervenich, G. Kirov, N. Akula, A. Dimitrova, E. Green, J. Schumacher, N. Klopp, T. Becker, S. Ohlraun, T.G. Schulze, M. Tullius, M.M. Gross, L. Jones, S. Krastev, I. Nikolov, M. Hamshere, I. Jones, P.M. Czerski, A. 
Leszczynska-Rodziewicz, P. Kapelski, A.V. Bogaert, T. Illig, J. Hauser, W. Maier, W. Berrettini, W. Byerley, W. Coryell, E.S. Gershon, J.R. Kelsoe, M.G. McInnis, D.L. Murphy, J.I. Nurnberger, T. Reich, W. Scheftner, M.C. O'Donovan, P. Propping, M.J. Owen, M. Rietschel, M.M. Nothen, F.J. McMahon, N. Craddock, Lack of support for a genetic association of the XBP1 promoter polymorphism with bipolar disorder in probands of European origin. Nat Genet 36 (2004) 783-784.

[4] A. Cravchik, D. Goldman, Neurochemical individuality: genetic diversity among human dopamine and serotonin receptors and transporters. Arch Gen Psychiatry 57 (2000) 1105-1114.

[5] R.P. Ebstein, J. Benjamin, R.H. Belmaker, Personality and polymorphisms of genes involved in aminergic neurotransmission. Eur J Pharmacol 410 (2000) 205214.

[6] R. Hashimoto, M. Yoshida, N. Ozaki, Y. Yamanouchi, N. Iwata, T. Suzuki, T. Kitajima, M. Tatsumi, K. Kamijima, H. Kunugi, Association analysis of the 308G > A promoter polymorphism of the tumor necrosis factor alpha (TNF-a ) gene in Japanese patients with schizophrenia. J Neural Transm 111 (2004) 217221.

[7] S.J. Hou, F.C. Yen, C.Y. Cheng, S.J. Tsai, C.J. Hong, X-box binding protein 1 (XBP1) C-116G polymorphisms in bipolar disorders and age of onset. Neurosci Lett 367 (2004) 232-234. 
[8] C. Kakiuchi, K. Iwamoto, M. Ishiwata, M. Bundo, T. Kasahara, I. Kusumi, T. Tsujita, Y. Okazaki, S. Nanko, H. Kunugi, T. Sasaki, F. Kato, Impaired feedback regulation of XBP1 as a genetic risk factor for bipolar disorder. Nature Genetics 35 (2003) 171-175.

[9] C. Kato, C. Kakiuchi, T. Umekage, M. Tochigi, N. Kato, T. Kato, T. Sasaki, XBP1 gene polymorphism (-116C/G) and personality. Am J Med Genet 136B (2005) 103-105.

[10] N. Kijima, R. Saito, M. Takeuchi, A. Yoshino, Y. Ono, M. Kato, T. Kitamura, Cloninger's seven-factor model of temperament and character and Japanese version of Temperament and Character Inventory (TCI). Jap J Psychiatr Diag 7 (1996) 379-399.

[11] W. Paschen, A. Frandsen, Endoplasmic reticulum dysfunction: a common denominator for cell injury in acute and degenerative diseases of the brain. $\mathrm{J}$ Neurochem 79 (2001) 719-725.

[12] K. Yoshimura, K. Nakamura, Y. Ono, A. Sakurai, N. Saito, M. Mitani, K. Yamauchi, N. Onoda, M. Asai, Reliability and validity of a Japanese version of the NEO Five Factor Inventory (NEO-FFI): a population-based survey in Aomori prefecture. Jap J Stress Sci 13 (1998) 39-47. 
Table I. TCI scores in healthy subjects sorted by $-116 \mathrm{C} / \mathrm{G}$ polymorphism of XBP1 gene

\begin{tabular}{cccccc}
\hline Sample & TCI subscales & \multicolumn{3}{c}{ XBP1 polymorphism } & ANCOVA \\
\cline { 3 - 4 } Total & (N=248) & $\mathrm{C} / \mathrm{N}=24)$ & $\mathrm{C} / \mathrm{G}=116)$ & $(\mathrm{N}=108)$ & \\
& Novelty Seeking & $50.7 \pm 4.9$ & $50.1 \pm 6.0$ & $50.2 \pm 7.0$ & $\mathrm{~F}=0.10, \mathrm{p}=0.91$ \\
& Harm Avoidance & $54.1 \pm 8.5$ & $52.7 \pm 7.7$ & $53.4 \pm 9.0$ & $\mathrm{~F}=0.36, \mathrm{p}=0.70$ \\
& Reward Dependence & $43.5 \pm 4.9$ & $43.2 \pm 5.2$ & $42.9 \pm 4.9$ & $\mathrm{~F}=0.34, \mathrm{p}=0.71$ \\
& Persistence & $12.5 \pm 2.1$ & $13.2 \pm 2.9$ & $12.8 \pm 2.7$ & $\mathrm{~F}=1.47, \mathrm{p}=0.23$ \\
& Self-Directedness & $68.4 \pm 10.0$ & $71.3 \pm 9.6$ & $69.3 \pm 10.0$ & $\mathrm{~F}=1.67, \mathrm{p}=0.19$ \\
& Cooperativeness & $72.8 \pm 5.8$ & $71.8 \pm 6.7$ & $71.3 \pm 6.7$ & $\mathrm{~F}=0.29, \mathrm{p}=0.75$ \\
& Self-Transcedence & $26.8 \pm 4.9$ & $28.0 \pm 6.4$ & $26.9 \pm 5.6$ & $\mathrm{~F}=1.30, \mathrm{p}=0.28$ \\
\hline Male & (N=141) & $(\mathrm{N}=7)$ & $(\mathrm{N}=71)$ & $(\mathrm{N}=63)$ & \\
& Novelty Seeking & $48.9 \pm 3.4$ & $49.9 \pm 6.0$ & $50.1 \pm 6.0$ & $\mathrm{~F}=0.30, \mathrm{p}=0.74$ \\
& Harm Avoidance & $51.6 \pm 4.5$ & $52.5 \pm 8.0$ & $51.8 \pm 8.3$ & $\mathrm{~F}=0.43, \mathrm{p}=0.65$ \\
& Reward Dependence & $42.4 \pm 4.9$ & $42.6 \pm 5.4$ & $42.1 \pm 4.8$ & $\mathrm{~F}=0.43, \mathrm{p}=0.65$ \\
& Persistence & $13.4 \pm 1.7$ & $13.5 \pm 2.8$ & $12.6 \pm 2.8$ & $\mathrm{~F}=2.02, \mathrm{p}=0.14$ \\
& Self-Directedness & $67.4 \pm 6.9$ & $69.8 \pm 10.5$ & $69.0 \pm 10.1$ & $\mathrm{~F}=0.10, \mathrm{p}=0.91$ \\
& Cooperativeness & $71.9 \pm 7.0$ & $71.1 \pm 7.3$ & $70.6 \pm 6.5$ & $\mathrm{~F}=0.14, \mathrm{p}=0.87$ \\
& Self-Transcedence & $25.7 \pm 4.3$ & $27.9 \pm 6.6$ & $26.8 \pm 5.7$ & $\mathrm{~F}=0.54, \mathrm{p}=0.58$ \\
\hline Female & (N=107) & $(\mathrm{N}=17)$ & $(\mathrm{N}=45)$ & $(\mathrm{N}=45)$ & \\
& Novelty Seeking & $51.4 \pm 5.3$ & $50.3 \pm 6.1$ & $50.3 \pm 8.2$ & $\mathrm{~F}=0.16, \mathrm{p}=0.85$ \\
& Harm Avoidance & $55.2 \pm 9.6$ & $52.2 \pm 7.4$ & $55.7 \pm 9.5$ & $\mathrm{~F}=1.97, \mathrm{p}=0.15$ \\
& Reward Dependence & $43.9 \pm 3.6$ & $44.2 \pm 4.6$ & $44.0 \pm 4.8$ & $\mathrm{~F}=0.03, \mathrm{p}=0.97$ \\
& Persistence & $12.1 \pm 2.2$ & $12.8 \pm 3.1$ & $13.2 \pm 2.5$ & $\mathrm{~F}=1.25, \mathrm{p}=0.29$ \\
& Self-Directedness & $68.8 \pm 10.3$ & $73.7 \pm 7.2$ & $69.6 \pm 10.4$ & $\mathrm{~F}=3.03, \mathrm{p}=0.05$ \\
& Cooperativeness & $73.2 \pm 5.4$ & $72.8 \pm 5.5$ & $72.3 \pm 7.0$ & $\mathrm{~F}=0.17, \mathrm{p}=0.84$ \\
& Self-Transcedence & $27.2 \pm 5.2$ & $28.2 \pm 6.3$ & $27.0 \pm 5.6$ & $\mathrm{~F}=0.49, \mathrm{p}=0.61$ \\
\hline TCI & & & & \\
\hline
\end{tabular}

TCI scores are expressed as the Mean \pm SD 
Table II. NEO-FFI scores in healthy subjects sorted by -116C/G polymorphism of XBP1 gene

\begin{tabular}{cccccc}
\hline Sample & NEO-FFI subscales & \multicolumn{3}{c}{ XBP1 polymorphism } & \multirow{2}{*}{ ANCOVA } \\
\cline { 2 - 4 } & & $\mathrm{C} / \mathrm{C}$ & $\mathrm{C} / \mathrm{G}$ & $\mathrm{G} / \mathrm{G}$ & \\
\cline { 2 - 4 } Total & (N=206) & $(\mathrm{N}=20)$ & $(\mathrm{N}=98)$ & $(\mathrm{N}=88)$ & \\
& Neuroticism & $29.4 \pm 8.1$ & $25.0 \pm 6.7$ & $26.2 \pm 7.7$ & $\mathrm{~F}=1.97, \mathrm{p}=0.14$ \\
& Extraversion & $23.2 \pm 5.5$ & $24.2 \pm 9.1$ & $22.0 \pm 6.3$ & $\mathrm{~F}=2.28, \mathrm{p}=0.11$ \\
& Openness & $29.6 \pm 6.5$ & $29.2 \pm 5.4$ & $29.1 \pm 5.0$ & $\mathrm{~F}=0.05, \mathrm{p}=0.95$ \\
& Agreeableness & $30.0 \pm 5.4$ & $28.4 \pm 5.6$ & $28.6 \pm 5.0$ & $\mathrm{~F}=0.51, \mathrm{p}=0.60$ \\
& Conscientiousness & $24.7 \pm 8.5$ & $26.3 \pm 7.0$ & $24.5 \pm 5.8$ & $\mathrm{~F}=1.50, \mathrm{p}=0.23$ \\
\hline Male & (N=119) & $(\mathrm{N}=7)$ & $(\mathrm{N}=61)$ & $(\mathrm{N}=51)$ & \\
& Neuroticism & $23.7 \pm 8.6$ & $25.1 \pm 6.9$ & $24.9 \pm 7.8$ & $\mathrm{~F}=0.47, \mathrm{p}=0.62$ \\
& Extraversion & $24.3 \pm 5.5$ & $24.2 \pm 10.6$ & $21.8 \pm 5.7$ & $\mathrm{~F}=1.25, \mathrm{p}=0.29$ \\
& Openness & $28.9 \pm 7.3$ & $29.2 \pm 5.7$ & $28.6 \pm 5.5$ & $\mathrm{~F}=0.08, \mathrm{p}=0.92$ \\
& Agreeableness & $31.6 \pm 4.7$ & $28.2 \pm 5.9$ & $27.8 \pm 5.2$ & $\mathrm{~F}=1.45, \mathrm{p}=0.24$ \\
& Conscientiousness & $29.7 \pm 8.4$ & $26.7 \pm 6.8$ & $24.2 \pm 5.7$ & $\mathrm{~F}=2.87, \mathrm{p}=0.06$ \\
\hline Female & (N=87) & $(\mathrm{N}=13)$ & $(\mathrm{N}=37)$ & $(\mathrm{N}=37)$ & \\
& Neuroticism & $32.5 \pm 6.2$ & $25.0 \pm 6.3$ & $28.1 \pm 7.4$ & $\mathrm{~F}=6.41, \mathrm{p}=0.003$ \\
& Extraversion & $22.6 \pm 5.7$ & $24.2 \pm 6.1$ & $22.3 \pm 7.2$ & $\mathrm{~F}=0.69, \mathrm{p}=0.51$ \\
& Openness & $30.0 \pm 6.3$ & $29.3 \pm 4.9$ & $29.7 \pm 4.2$ & $\mathrm{~F}=0.15, \mathrm{p}=0.86$ \\
& Agreeableness & $29.1 \pm 5.7$ & $28.9 \pm 5.1$ & $29.6 \pm 4.7$ & $\mathrm{~F}=0.15, \mathrm{p}=0.87$ \\
& Conscientiousness & $22.0 \pm 7.5$ & $25.6 \pm 7.3$ & $24.8 \pm 6.0$ & $\mathrm{~F}=1.32, \mathrm{p}=0.27$ \\
\hline
\end{tabular}

NEO-FFI scores are expressed as the Mean \pm SD 